\title{
EFFECTS OF A RATIONING RULE ON THE AUSUBEL AUCTION: A GENETIC ALGORITHM IMPLEMENTATION
}

\author{
YAGo SAEZ, DAVID QUINTANA, AND PEDRo ISASI \\ Department of Computer Science, Universidad Carlos III de Madrid, Leganes, Madrid, Spain \\ ASUNCION MOCHON \\ Department of Applied Economics, UNED, Madrid, Spain
}

\begin{abstract}
The increasing use of auctions as a selling mechanism has led to a growing interest in the subject. Thus both auction theory and experimental examinations of these theories are being developed. A recent method used for carrying out examinations on auctions has been the design of computational simulations. The aim of this article is to develop a genetic algorithm to find automatically a bidder optimal strategy while the other players are always bidding sincerely. To this end a specific dynamic multiunit auction has been selected: the Ausubel auction, with private values, dropout information, and with several rationing rules implemented. The method provides the bidding strategy (defined as the action to be taken under different auction conditions) that maximizes the bidder's payoff. The algorithm is tested under several experimental environments that differ in the elasticity of their demand curves, number of bidders and quantity of lots auctioned. The results suggest that the approach leads to strategies that outperform sincere bidding when rationing is needed.
\end{abstract}

Key words: genetic algorithm, Ausubel auction, dynamic multi-unit, rationing values, bidder strategy.

\section{INTRODUCTION}

Motivated by the enhanced use of auction, the present work reports a computational experiment of a specific ascending multiunit auction, the Ausubel auction (Ausubel 1997, 2004). In the framework considered, bidders have independent private values and full bid information. In these experiments all bidders, except one, always bid sincerely, i.e., according to their true values. Nevertheless, there is one bidder (the strategic bidder) that behaves according to a genetic algorithm (GA) that learns from one round to another. The results suggest that the GA developed can achieve higher payoffs than bidding sincerely when he can take advantage of the rationing rule. To test the GA, several rationing rules have been considered. The strategic bidder finds an optimal strategy that differs from equilibrium (sincere bidding) once he learns his rivals' behavior and the rationing rule. This bidder tends to end the auction early to increase his gains.

This result can be interesting for future researches as auctions are extensively used as selling mechanism in different markets around the world. The items or lots auctioned range from the wide variety being offered on Internet marketplaces like eBay; the government auctions of spectrum rights, treasury bills, electricity, emission permits; or the auctions of art, financial assets, agricultural goods, etc. As a result of these activities, auction theory and experimental examinations of these theories are of growing interest. It is very difficult to list the numerous articles on auctions. However, some of the relevant references are Klemperer (2000, 2003), Krishna (2002), Milgrom (2004), etc.

Auction theory is founded on the dual assumptions of rational behavior and equilibrium. It gives players some prescriptive guidance of how they should play. Nevertheless, a number of social scientists challenge the rationality assumption, and argue that it should not be taken for granted as subjects sometimes make systematic errors in their strategies (Andreoni and Miller 1995). Therefore, an alternative must be reached to search for the best strategies but without assuming perfectly calculating rationality on players. The biological theory of evolution might be a key point in this challenge.

Biological theory rests on three fundamentals: heterogeneity, fitness, and selection. An important part of animals behavior is genetically determined by one or more genes (genotype) 
that govern a particular pattern of behavior (phenotype or strategy). The pool of genes ensures heterogeneity of phenotypes in the population, for which success is given a quantitative measure called its fitness. The fitness of a particular strategy is defined as its aggregate or average payoff in its matching with all the strategies in the population. The process of selection makes the fitter phenotypes become relatively more numerous in the next generation. Changes produce new genetic mutations that can lead to a new and fitter phenotype and successfully invade the population of strategies, i.e., spread so as to become a significant proportion of the population.

A recent method used for analyzing strategies on auctions is by means of systems of artificial adaptive agents (AAA). The analysis of these systems gives us new approaches to the understanding of the economic and social behavior of auctions. In this way, the use of machine learning systems could help in the finding of optimal strategies or in the evaluation, from different points of view, of the auction itself with respect to other possible auctions. In this context, genetic algorithms (GAs) are a good learning method. GAs are a robust method of adaptive searching, learning, and optimization in complex problem domains. In recent years, GAs have been used in research that includes auctions. Some examples are Andreoni and Miller (1995), Dawid (1999), Numnonda and Annakkage (1999), Wen and David (2001), Anthony and Jennings (2002, 2003), Cliff (2003), Mochon et al. (2005a), etc.

This article focuses on a particular specification of a multiple-object ascending-clock auction developed by Ausubel $(1997,2004)$, which is usually known as the Ausubel auction. In this auction, with private values and diminishing marginal utilities, sincere bidding by every bidder constitutes an equilibrium, i.e., bidders bid according to their true value. Some other authors have studied this auction format. A modification of the Ausubel auction with asymmetric bidders and interdependent values has been done in Perry and Reny (2002, 2005). It has also been tested that the auction corresponds to the implementation of a marginal product pricing equilibrium via the primal-dual algorithm (Bikhchandani and Ostroy 2006). Moreover, this auction format has been frequently compared with other multiunit auctions. An experimental comparison has been done with the static multiunit auction analyzed by Vickrey (1961) both for private and common value (Manelli, Sefton, and Wilner 2000). Furthermore, the Vickrey auction and the Ausubel format with and without dropout information during the auction have been tested (Kagel and Levin 2001; Kagel, Kinross, and Levin 2004). An experimental study has been conducted with four different auction formats: sealed-bid Vickrey auction, Ausubel auction with dropout information provided, survival auction, and two-stage survival auction to compare the outcomes (Kagel, Ye, and Pevnitska 2004). Additionally pros and cons of the standard ascending-clock auction and the Ausubel auction have been evaluated in a setting where the authorities wished to allocate exclusive rights such as emission permits efficiently evaluated (Sunnevag 2001). A laboratory experiment has also been presented to analyze the revenue equivalence for different multiunit auction mechanisms including the Ausubel mechanism (Dirk and Grimm 2004).

The present article reports a computational experiment comparing bidders payoff for the Ausubel auction with private values and dropout information. The aim of this research is to find out whether the best strategy for one bidder can be achieved automatically, by means of GAs with the rationing rules considered, while his rivals are bidding sincerely. In fact, the results suggest that, sometimes, the bidder that learns how to bid with the GA, finally acts strategically to end the auction early to take advantage of the rationing rule. With these bidding strategies, this bidder earns higher payoffs than bidding sincerely. The fact that rationing or tie-breaking rules may have a significant effect on the final outcome of an auction is not new. Some authors have explored the effect on bidding behavior and equilibrium revenues under two distinct rationing rules for the European Central Bank auctions (Gresik 2001). Moreover, the importance of the rationing rule to establish the existence of an equilibrium 
in many games, including auctions, has also been analyzed (Simon and Zame 1990; Jackson et al. 2002).

The remainder of the article is structured in the following manner. A definition of the auction model selected is given in section 2. Three rationing rules are considered in this section: the proportional rationing rule, the spread rationing rule, and the concentrate rationing rule. In section 3 the experimental environment, the fundamentals of the bidding algorithm, and the auction conditions that affect its performance are described. Section 4 evaluates the experimental results in several environments by comparing the bidders payoff and the seller's revenue that yields the GA strategy with those obtained if all bidders bid sincerely. The optimal bidding strategy that the GA proposes, which outperforms sincere bidding is also analyzed. To that end the bidders' behavior in six different experiments per each tie-breaking rule has been analyzed deeply. In section 5 the main conclusions and future work are presented.

\section{THE AUSUBEL AUCTION FORMAT}

This article focuses on a particular specification of rules for what might be referred to generically as an "ascending-clock auction." In the standard ascending-clock auction, where demands are required to be non incremental in price, the auctioneer employs a price "clock" that starts at zero (or at a low price) and increases continuously thereafter. For each price, $p$, each bidder $i$ simultaneously indicates the quantity $q_{i}(p)$ he desires. When the price $p^{*}$ is reached, such that aggregate demand no longer exceeds supply, or until the exogenous ending time is reached, whichever occurs sooner, the auction is over. Each bidder $i$ is then assigned the quantity $q_{i}\left(p^{*}\right)$ and is charged a unit price of $p^{*}$.

The description of the alternative ascending-bid auction developed by Ausubel (1997, 2004) coincides with this auction format where bidders choose at what price to drop out of the bidding, with dropping out being irrevocable. What is not specified, however, are the payments owed to each of the winners. As it has been mentioned, when the auction is over each bidder $i$ is assigned the quantity $q_{i}\left(p^{*}\right)$ but is charged the standing prices at which the respective objects were "clinched." With $M$ objects for sale at a price $p_{1}$, bidder $i$ clinches an object when the aggregate demand of all other bidders is lowered, at least, from $M$ to $M-1$ but bidder $i$ still demands two units or more. This is, when the demand of all bidders except him is smaller than the total supply but the total demand exceeds the total supply. In this situation bidder $i$ is guaranteed at least one object no matter how the auction proceeds. In this way the auction sequentially implements the Vickrey rule that says each bidder pays the amount of the $k^{\text {th }}$ highest rejected bid, other than his own, for the $k^{\text {th }}$ object won.

The Ausubel auction provides several information rules: with and without dropout information. In the first one, dropout prices are announced as they occur, along with announcements of items earned (or clinched) and prices paid, as the auction proceeds. In the second one, winners and prices paid are not announced until the auction has ended. For a better understanding of the allocation and payment rule of this mechanism, Appendix A includes two examples of the Ausubel auction. In the first one, participants bid sincerely and in the second one, bidder 1 bids according to the GA.

To be able to define the auction outcome, it is necessarily to make first a basic specification of the model from the formulation in Ausubel (1997), considering all discrete variables. In each auction the seller offers $M$ number of indivisible units of a homogeneous good to $n$ bidders. Each bidder $i$ obtains a marginal value of $v_{i, k}$ for the $k^{\text {th }}$ unit of the good, for $k=1, \ldots, M$. Thus if bidder $i$ gets $q_{i}^{*}$ units for a total payment of $P_{i}^{*}$, he obtains a payoff of: 


$$
\sum_{k=1}^{q_{i}^{*}} v_{i, k}-P_{i}^{*}, \text { for } i=1, \ldots, n \text { and } q_{i}=1, \ldots, M .
$$

All bidders are assumed to exhibit (weakly) diminishing marginal values, i.e., $v_{i, k} \geq v_{i, k+1} \geq 0$, for all $i=1, \ldots, n$, which are privately observed by the respective bidders, making this game one of incomplete information. The estimation of the own value made by bidder $i$ is not affected by bidder $j$ 's valuation. As it is explained in the next section, bidders marginal values are generated randomly from an uniform distribution and are statistically independent of each other for $i \neq j$.

In the model it is assumed that all bidders have full bid information. This means that bidders have the complete history of all bids made by all bidders in the auction. This specification of the Ausubel auction with dropout information is sometimes referred as the Ausubel-Plus auction (Kagel, Kinross, and Levin 2004).

For any round $l$, the aggregate demand by all bidders is $Q^{l}=\sum_{i} q_{i}^{l}$. Hence, the cumulative vector of quantities $C_{i}^{l}$ clinched by bidder $i$ at prices up to $p^{l}$ is defined by equation (2).

$$
C_{i}^{l}=\max \left\{0, M-\sum_{j \neq i} q_{j}^{l}\right\}, \text { for } l=1, \ldots, L \text { and } i=1, \ldots, n .
$$

Setting $c_{i}^{0}=C_{i}^{0}$, the individual quantities clinched by each bidder at price $p^{l}$ are defined as follows:

$$
c_{i}^{l}=C_{i}^{l}-C_{i}^{l-1}, \text { for } l=1, \ldots, L \text { and } i=1, \ldots, n .
$$

The auction outcome associated with any final history $l=L$ is defined in equations (4) and (5).

$$
\begin{gathered}
\text { Allocation : } q_{i}^{*}=C_{i}^{l}, \text { for } l=1, \ldots, L . \\
\text { Payment : } P_{i}^{*}=\sum_{l=0}^{L} p^{l} c_{i}^{l}, \text { for } l=1, \ldots, L .
\end{gathered}
$$

In the same way, the seller's revenue per auction is defined as the total payments done by all bidders revenue:

$$
R^{*}=\sum_{i=l}^{N} P_{i}^{*}, \text { for } l=1, \ldots, L .
$$

Ausubel (2004) demonstrated that in this auction format with pure private values, sincere bidding by every bidder is an ex post perfect equilibrium yielding an efficient outcome. Notwithstanding, truthful bidding is not the unique equilibrium, as there may exist other equilibria.

In the model presented in this work, all but one bidder have a fixed bidding strategy: sincere bidding. There is only one bidder whose strategy depends on the process of the auction. This single bidder evolves according to a GA that learns the best strategy to implement from one auction to another and that indicates how the bidder should bid according to its results.

\subsection{Rationing Rules}

As price goes up and demanded quantities go down, it is possible that, for a certain increase of price, the supply is not covered at the final price $\left(Q^{L}<M\right)$. In these circumstances 
a rationing rule is introduced, consistent with $q_{i}^{L} \leq q_{i}^{*} \leq q_{i}^{L-1}$ and $\sum_{i=1}^{n} q_{i}^{*}=M$. Moreover, items clinched cannot be taken away form a bidders under the rationing rule. In this article three different rationing rules have been considered.

The first rationing rule applied is one of the most commonly used in the literature, that is, the proportional rationing rule (PRR). This rule establishes that when the supply is not covered at price $p^{L}$, the allocation of the items is made according to equation (7):

$$
C_{i}^{L}=q_{i}^{L}+\left[\frac{q_{i}^{L-1}-q_{i}^{L}}{Q^{L-1}-Q^{L}}\right]\left(M-Q^{L}\right) .
$$

As all variables are considered integers, sometimes when the rationing is applied, the items clinched must be rounded up.

Ausubel pointed out that the rationing rule may be specified relatively arbitrarily, but it must satisfy the following monotonicity property (Ausubel 2004). If $q^{L}<q^{L-1}$, then the expected quantity $E\left[q^{*}\right]$ assigned to bidder $i$ must be strictly greater than his final bid $q^{L}$. The PRR satisfies this property.

In the second and third rationing rules considered, when the supply is not covered at price $p^{L}$, the seller turns to the previous price $\left(p^{L-1}\right)$ and allocates all the demanded units to the bidders. Then the excess demand $\left(Q^{L-1}-M\right)$ is calculated, which is removed from the bidders in two different ways. The final quantities allocated to the respective bidders are defined by equation (8):

$$
D_{i}^{L}=q_{i}^{L-1}-\lambda\left(Q^{L-1}-M\right)
$$

Before removing units, the difference between the bidders demand and what they have already clinched is calculated for each bidder. This demand not satisfied in round $L-1$ is equal to $s_{i}^{L-1}=q_{i}^{L-1}-C_{i}^{L-1}$.

In the second rationing rule, $\lambda$ is calculated by removing one unit from the bidders with the highest $s_{i}^{L-1}$, until the total demand equals supply. This rule yields a final allocation that spreads the items among bidders. Therefore, it will be named as the spread rationing rule (SRR). The third rationing rule works just like the previous one but $\lambda$ is calculated in a different manner. Units are removed from bidders with the lowest $s_{i}^{L-1}$, until the total demand equals supply. This rule will favor the concentration of items among bidders. Hence, it will be named as the concentrate rationing rule (CRR).

\section{DESIGNING THE GA FOR THE BIDDING STRATEGY}

GAs have proven to be a powerful method to search nonlinear problems for better solutions in many domains (Mitchell 1996). The aim of the GA proposed in this work is to find a set of bidding rules that maximize the payoff of a bidder according to equation (1). To this end several experimental environments have been defined for which each bidder has a different set of values and a specific bidding strategy. Some authors have already used similar approaches to compare bidding strategies in auctions (Andreoni and Miller 1995). These authors used a GA to test the bidding behavior among participants for the first and second-price auctions with affiliated private-values, interdependent private-values, and common values. 


\subsection{Defining the Experimental Environments}

The experiment employs an independent-private-value (IPV) framework in which bidders have weakly diminishing marginal values, are risk neutral and have no budget constraints. In the experiments done with this auction format, all bidders except one have a fixed strategy, which is truthful bidding. Therefore, bidders will reduce their demanded quantities just when the actual price is equal to their real values. On the other hand, the bids of the strategic bidder who follows the GA will depend on several actions that are defined as deviations from bidding sincerely.

The bidders bidding behavior is explored in several environments that differ in the following variables: the number of lots auctioned $(M)$, the number of bidders $(n)$, and the elasticity of the bidders demand curves: elastic and inelastic. The number of lots auctioned and the number of bidders are considered as external variables for the following values: $M=10,15,20$, and $25 ; n=4,6$ and 8 . The elasticity of the bidders demand curve depends on their private valuations of the items, which are generated as it is described below.

Every bidder has a set of values organized from higher to lower that specify the marginal value from the consumption of each additional unit. The model forces each bidder to define his values for at least as many items as the total supply. Bidders' values are drawn independently and identically distributed from an uniform distribution with support [0, 200], with new random draws for each additional unit. These values are generated with two different algorithms, in the same way as Mochon et al. (2005b).

\subsection{Defining the Bidding Strategy}

In each auction all bidders are programmed to bid their true value. There is only one bidder that has to beat his computer rivals by following the GA bidding strategy. The definition of the GA strategy requires the identification of actions linked to specific auction conditions. Each action is defined in terms of deviations (over- and underbidding) from the sincere bidding strategy. The demanded quantity according to the sincere bidding strategy of bidder $i$ in the round $l$ is represented by $q_{S B_{i}}^{l}$. There are four possible actions to be taken: bid half of the sincere bidding quantity $\left(q_{S B_{i}}^{l} / 2\right)$; bid the sincere bidding quantity $\left(q_{S B_{i}}^{l}\right)$; bid $50 \%$ more of the sincere bidding quantity $\left(q_{S B_{i}}^{l} * 1.5\right)$; or bid twice as much as the sincere bidding quantity $\left(q_{S B_{i}}^{l} * 2\right)$.

The bidder that evolves with the GA strategy will bid one of these four actions according to the auction condition of each round. All these strategies have an upper bound that is the lowest of either the number of units being auctioned or, alternatively, the units demanded in the previous round (as demand is required to be nonincreasing). The lower bound is the number of units that the participant has already clinched.

Bidders face 61 possible auction conditions. The first one represents the initial market where no relevant information is available. A combination of the potential values of three different indicators is done to define the other 60 possible auction conditions. In each auction the value of these indicators changes from one round to another. As the auction format has dropout information, the bidder that follows the GA strategy constantly calculates these indicators and selects the appropriate action or bid.

The first indicator is the trend of price-demand elasticity from the competitors $\left(\varepsilon_{p, d}\right)$, classified into these categories: $[0,0.5),[0.5,1), 1,(1,1.5),[1.5,+\infty)$. The second one is the percentage of active bidders with respect to the number of bidders at the beginning of the auction (AB\%), classified in the following intervals: [0, 25\%), [25\%, 50\%), [50\%, 100\%]. And the third indicator is the operating margin of the strategic bidder (OM), defined as the 
number of objects that have not been clinched with respect to the number of objects demanded by the bidder. It has been classified into four intervals: $[0,1),[1,1.25),[1.25,2),[2,+\infty)$. For a better understanding of these indicators see Mochon et al. (2005a).

\subsection{Defining the Genetic Algorithm}

The encoding of the bidding strategies to the individuals is a direct process. As it was mentioned before, all strategies consist of a set of 61 integers valued from 0 to 3, depending on the action to be taken, which depends on the auction conditions. Because the actions can be encoded in two bits, each strategy could be represented as an array of 122 bits. This includes the sincere bidding strategy, $q_{S B_{i}}^{l}$. Because the action of following the sincere bidding strategy is defined as $1(01)$, the strategy of a bidder would be represented as a string of 122 bits (where the value of every odd bit is 0 and 1 otherwise).

Therefore, an individual is a bidding strategy that takes into account all the possible auction conditions and specifies the amount to bid for each of these. For example, the strategy 001.. (until 122) could represent something like:

If $\left(\varepsilon_{p, d} \in[1.5,+\infty]\right)$ and $(A B \% \in[50 \%, 100 \%])$ and $(O M \in[2,+\infty])$, then bid half of sincere bidding, $\left(q_{S B_{i}}^{l} / 2\right)$

If $\left(\varepsilon_{p, d} \in[1.5,+\infty]\right)$ and $(A B \% \in[50 \%, 100 \%])$ and $(O M \in[1.25,2])$, then bid $50 \%$ more that sincere bidding, $\left(q_{S B_{i}}^{l} * 1.5\right)$

$\ldots$ and so on.

The assessment of a bidding strategy is made by running an auction twice. In the first run all bidders follow sincere bidding. In the second one, a bidder (bidder 1) evolves according to the GA and the others just bid sincerely. Once the allocations and payments for each bidder are obtained, the payoff for the strategic bidder for both runs according to equation 1 is calculated. The GA strategy will succeed if the payoff for bidder 1 is higher in the second run rather than in the first one, no matter what the others bidders' payoff or the seller's revenue. To search for the best strategy for each environment the GA used a population of 30 individuals that evolved for 1,000 generations. After several auctions or generations, bidder 1 realizes which are the private values of the other participants and finds his optimal strategy to beat them.

The GA is implemented with the parameters showed in Table 1. The selection operator is a roulette wheel selection mechanism with elitism. The mutation and single-point crossover probabilities were set to 0.01 and 0.9 , respectively. Crossover, and mutation are simple mechanisms for agents or individuals to modify their existing strategies based on past

TABLE 1. Parameters Used for the Experiments

\begin{tabular}{llc}
\hline Algorithm & \multicolumn{1}{c}{ Canonical } \\
\hline Population & (SimpleGA from GALib) & N/A \\
Encoding & 30 Individuals & N/A \\
Selection & Vector of bits & 122 \\
Crossover & Roulette & N/A \\
Mutation & Single point & $90 \%$ \\
\hline
\end{tabular}


experience. Crossover allows an individual to create a new strategy by borrowing parts of previously successful strategies. Mutation allows an individual to make small modifications in old strategies in hopes of finding a better strategy.

Different selection, crossover, and mutation operators have been tested with similar results. The search space is large $2^{122} \simeq 5 * 10^{35}$, but a lot of strategies are equivalent decreasing significatively the target search space. Besides, the GAs performance is good enough to avoid spending time tuning the GA parameters for testing different operator mechanisms, and the correct parameters used with the appropriate operator could be an optimization problem itself.

\section{EVALUATING THE BIDDING STRATEGY}

In this section the outcome obtained by the GA strategy is evaluated. The experiments have been run for all the environments described in section 3 and the rationing rules explained in section 2. For each rationing rule, the algorithm was run for all the environments 25 times, letting a population of 30 individuals evolve for 1,000 generations.

To evaluate the GA strategy, the payoff of the GA bidder is compared with respect to what he would have obtained with the sincere bidding strategy. Table 2 reports the strategic bidder payoff (bidder 1) for these two strategies when the PRR is applied. The unit of observation

TABLE 2. Payoff Average for Sincere Bidding (SB) and GA Bidding Strategies with CRR

\begin{tabular}{|c|c|c|c|c|c|c|c|c|}
\hline & \multicolumn{2}{|c|}{$m=10$} & \multicolumn{2}{|c|}{$m=15$} & \multicolumn{2}{|c|}{$m=20$} & \multicolumn{2}{|c|}{$m=25$} \\
\hline & SB & GA & SB & GA & SB & GA & SB & GA \\
\hline $\begin{array}{l}\text { Elastic } \\
n=4\end{array}$ & $\begin{array}{l}138.96 \\
(24.17)\end{array}$ & $\begin{array}{c}139.12 \\
(24.18) \\
\mathbf{0 . 1 6}\end{array}$ & $\begin{array}{c}207.68 \\
(35.04)\end{array}$ & $\begin{array}{c}209.08 \\
(34.98) \\
\mathbf{1 . 4 0}\end{array}$ & $\begin{array}{l}199.16 \\
(37.74)\end{array}$ & $\begin{array}{c}218.12 \\
(35.88) \\
\mathbf{1 8 . 9 8}\end{array}$ & $\begin{array}{l}279.44 \\
(36.43)\end{array}$ & $\begin{array}{c}286.80 \\
(34.84) \\
7.36\end{array}$ \\
\hline$n=6$ & $\begin{array}{c}65.16 \\
(12.98)\end{array}$ & $\begin{array}{c}66.76 \\
(13.32) \\
\mathbf{1 . 6 0}\end{array}$ & $\begin{array}{l}112.00 \\
(26.28)\end{array}$ & $\begin{array}{c}112.32 \\
(26.22) \\
\mathbf{0 . 3 2}\end{array}$ & $\begin{array}{l}140.84 \\
(27.40)\end{array}$ & $\begin{array}{c}140.92 \\
(27.38) \\
\mathbf{0 . 0 8}\end{array}$ & $\begin{array}{l}183.84 \\
(33.36)\end{array}$ & $\begin{array}{c}183.84 \\
(33.36) \\
\mathbf{0 . 0 0}\end{array}$ \\
\hline$n=8$ & $\begin{array}{c}73.56 \\
(23.18)\end{array}$ & $\begin{array}{c}73.80 \\
(23.19) \\
\mathbf{0 . 2 4}\end{array}$ & $\begin{array}{c}69.96 \\
(14.73)\end{array}$ & $\begin{array}{c}71.28 \\
(14.57) \\
\mathbf{1 . 3 2}\end{array}$ & $\begin{array}{c}97.24 \\
(18.25)\end{array}$ & $\begin{array}{c}97.92 \\
(18.44) \\
\mathbf{0 . 6 8}\end{array}$ & $\begin{array}{l}181.96 \\
(40.14)\end{array}$ & $\begin{array}{r}182.60 \\
(40.20) \\
\mathbf{0 . 6 4}\end{array}$ \\
\hline $\begin{array}{l}\text { Inelastic } \\
n=4\end{array}$ & $\begin{array}{l}133.04 \\
(16.69)\end{array}$ & $\begin{array}{c}133.64 \\
(16.69) \\
\mathbf{0 . 6 0}\end{array}$ & $\begin{array}{l}211.64 \\
(14.28)\end{array}$ & $\begin{array}{c}212.48 \\
(14.35) \\
\mathbf{0 . 8 4}\end{array}$ & $\begin{array}{c}264.12 \\
(18.78)\end{array}$ & $\begin{array}{c}264.76 \\
(18.85) \\
\mathbf{0 . 6 4}\end{array}$ & $\begin{array}{l}279.64 \\
(21.04)\end{array}$ & $\begin{array}{c}280.72 \\
(21.08) \\
\mathbf{1 . 0 8}\end{array}$ \\
\hline$n=6$ & $\begin{array}{c}89.40 \\
(12.14)\end{array}$ & $\begin{array}{c}89.80 \\
(12.18) \\
\mathbf{0 . 4 0}\end{array}$ & $\begin{array}{l}132.76 \\
(18.12)\end{array}$ & $\begin{array}{c}133.16 \\
(18.09) \\
\mathbf{0 . 4 0}\end{array}$ & $\begin{array}{l}176.00 \\
(15.77)\end{array}$ & $\begin{array}{c}176.44 \\
(15.76) \\
\mathbf{0 . 4 4}\end{array}$ & $\begin{array}{c}219.00 \\
(19.73)\end{array}$ & $\begin{array}{c}219.80 \\
(19.68) \\
\mathbf{0 . 8 0}\end{array}$ \\
\hline$n=8$ & $\begin{array}{l}35.32 \\
(6.24)\end{array}$ & $\begin{array}{c}36.68 \\
(6.49) \\
\mathbf{1 . 3 6}\end{array}$ & $\begin{array}{c}77.36 \\
(13.17)\end{array}$ & $\begin{array}{c}77.48 \\
(13.15) \\
\mathbf{0 . 1 2}\end{array}$ & $\begin{array}{l}132.28 \\
(13.84)\end{array}$ & $\begin{array}{c}132.36 \\
(13.88) \\
\mathbf{0 . 0 8}\end{array}$ & $\begin{array}{l}187.44 \\
(23.03)\end{array}$ & $\begin{array}{c}189.04 \\
(23.08) \\
\mathbf{1 . 6 0}\end{array}$ \\
\hline
\end{tabular}

Standard errors of the mean in parentheses. Payoff differences form SB in bold. 
employed is the mean of the payoff for each environment. The results display that the GA proposes a strategy, which yields to equal or higher payoffs than truthful bidding.

Appendix B includes the same sets of results for the SRR and the CRR. For the different environments explored with all the rationing rules considered, the GA strategy always yields an equal or higher payoff than bidding sincerely. These results reveal that, at least in some cases and for all the rationing rules compared, bidders' payoff can be improved by means of GA.

\subsection{Rationing Rules and Bidding Strategies with the GA}

One of the key points in this study is to find out the bidding strategy that the GA proposes. To this end, the process of six auctions is analyzed in detail for each rationing rule considered (PRR, SRR, and CRR), three of them with elastic demand curves and the other three inelastic. The specific environment of these auctions is: $n=4$ and $M=15$. This analysis verifies that both the auction process simulation and the GA applied work properly.

The auction process for an example with the PRR in which every bidder follows the sincere bidding strategy, and afterward the same auction runs again but with bidder 1 following the GA strategy, is included in Appendix A. In this auction, when the GA strategy of bidder 1 is compared with respect to the sincere bidding, it can observe that at the beginning of the auction the participant is overbidding. Particularly, in this example, his action or bid is equal to $q_{S B_{1}}^{l} * 2$ (code 11), i.e., he is bidding 10 when $q_{S B_{1}}^{l}$ is 5 . He continues overbidding just until he determines the best moment to underbid and push the auction to rationing. There are two main facts that affect this decision: (i) the demand of the other competitors $\left(q_{2}^{l}+q_{3}^{l}+q_{4}^{l}\right)$ plus what he has already clinched $\left(C_{1}^{l}\right)$ is equal to $M$, equation (9); and (ii) what he has already clinched plus what he will probably get if the rationing rule is applied in that round is equal to $q_{S B_{1}}^{l}$.

$$
\sum_{j \neq i} q_{j}^{l}+C_{1}^{l}=M .
$$

When equation (9) holds, it implies that the excess demand of the auction is equal to bidder $i$ bid minus what he has already clinched, $Q^{l}-M=q_{1}^{l}-C_{1}^{l}$. Therefore, by lowering his bid in the next round, he has a high probability of pushing the auction to a rationing situation. Moreover, as he learns how the tie-breaking rule works and his rivals' preferences, the bidder will also calculate the number of items that he will probably gets if the rationing rule is put into effect in that round. When what he has clinched plus what he will probably get with the rationing rule is connected with his true valuation, then it would be the moment to underbid.

At that point the best strategy for bidder 1, according to the GA, is to make his possible minimum bid in the next round, i. e., $q_{1}^{L}=C_{1}^{L-1}$. In this example he bids 2 when $q_{S B_{i}}^{l}$ is 3 , the participant is underbidding. By doing this, bidder 1 pushes the auction to rationing. With this behavior, the strategic bidder has changed the final prices at which the units have been clinched. Therefore, both the bidders' payments and the sellers' revenue have been modified. In the other examples with the PRR, SRR, and CRR the bidder with the GA strategy behaves in a very similar way. He usually starts overbidding until the GA finds the optimal round to push the auction to rationing according to the probability of force rationing and his final allocation of items with respect to his real valuations. At this stage, he makes his minimum bid, that is, $q_{1}^{L}=C_{1}^{L-1}$ and pushes the auction to rationing. For those specific auctions when $c_{1}^{L-1}=0$, bidder 1 will make his last bid equal to $q_{1}^{L}=\frac{q_{S B_{1}}^{L}}{2}$. 
TABLE 3. Effect of the GA Strategy with Respect to the Sincere Bidding (SB) Strategy for All Participants $(n=4, M=15)$

\begin{tabular}{|c|c|c|c|c|c|c|c|c|c|}
\hline & \multicolumn{3}{|c|}{ PRR } & \multicolumn{3}{|c|}{ SRR } & \multicolumn{3}{|c|}{ CRR } \\
\hline & $\begin{array}{c}\text { Seller } \\
\text { Revenue }\end{array}$ & $\begin{array}{c}\text { Bidder } 1 \\
\text { Payoff }\end{array}$ & $\begin{array}{c}\text { Others } \\
\text { Bidders } \\
\text { Payoff }\end{array}$ & $\begin{array}{c}\text { Seller } \\
\text { Revenue }\end{array}$ & $\begin{array}{l}\text { Bidder } \\
1 \text { Payoff }\end{array}$ & $\begin{array}{c}\text { Others } \\
\text { Bidders } \\
\text { Payoff }\end{array}$ & $\begin{array}{c}\text { Seller } \\
\text { Revenue }\end{array}$ & $\begin{array}{l}\text { Bidder } \\
1 \text { Payoff }\end{array}$ & $\begin{array}{c}\text { Others } \\
\text { Bidders } \\
\text { Payoff }\end{array}$ \\
\hline Elastic 1 & $0 \%$ & $1 \%$ & $0 \%$ & $-6 \%$ & $7 \%$ & $-9 \%$ & $-2 \%$ & $1 \%$ & $-7 \%$ \\
\hline Elastic 2 & $-15 \%$ & $2 \%$ & $0 \%$ & $-10 \%$ & $6 \%$ & $5 \%$ & $-5 \%$ & $6 \%$ & $-198 \%$ \\
\hline Elastic 3 & $-1 \%$ & $1 \%$ & $1 \%$ & $-0 \%$ & $4 \%$ & $-2 \%$ & $-473 \%$ & $34 \%$ & $-122 \%$ \\
\hline Elastic 1 & $-10 \%$ & $1 \%$ & $7 \%$ & $-8 \%$ & $3 \%$ & $-1 \%$ & $-6 \%$ & $4 \%$ & $-42 \%$ \\
\hline Elastic 2 & $3 \%$ & $1 \%$ & $-1 \%$ & $-14 \%$ & $3 \%$ & $3 \%$ & $-4 \%$ & $3 \%$ & $-7 \%$ \\
\hline Elastic 3 & $4 \%$ & $1 \%$ & $-2 \%$ & $-10 \%$ & $3 \%$ & $2 \%$ & $-1 \%$ & $3 \%$ & $-20 \%$ \\
\hline $\begin{array}{l}\text { Average } \\
\text { weighted }\end{array}$ & $-3.8 \%$ & $1.0 \%$ & $0.8 \%$ & $-8 \%$ & $4 \%$ & $0 \%$ & $-83 \%$ & $8 \%$ & $-66 \%$ \\
\hline
\end{tabular}

With these three rationing rules, the effect of the GA strategy on the participants involved in the auction for all analyzed examples is provided in Table 3 . The units of observation are the seller's revenues (equation 6), the payoff for bidder 1, and the payoff for all bidders except 1. All these variables are computed as a percentage of the difference from what they would have been by bidding sincerely.

In all examples considered, bidder 1 is always better off following the GA bidding strategy rather than bidding sincerely. With the SRR and CRR this difference is even more significant. $\mathrm{He}$ always wins at least the same number of objects and at a lower average price. With the PRR, bidder 1 always gets the same units but as he usually overbids, the units are clinched at lower prices. With the SRR and the CRR he clinches units at a lower prices and he often takes advantage of the rationing rules earning more units than with the sincere bidding strategy. Therefore, with these two rationing rules the payoff difference is higher.

The seller is always worse off with the SRR and the CRR as he does sell all the items but at a lower price. Hence the revenues are lower. Nevertheless, with the PRR there are some specific auctions where the seller is better off. The reason for this result is that with the strategic bidder behavior, the other participants sometimes clinch units at higher prices.

The final payoff for the other participants is always lower with the CRR. With the PRR and the SRR the final outcome depends on each specific auction. Sometimes they do have higher payoff as the average selling price of the items is lower. Nevertheless, their payoffs can also be reduced given that the prices at which they clinch are sometimes higher, and because they do not earn the same number of items, as bidder 1 takes advantage of the rationing rule. Since bidder 1 does not bid sincerely, another important result is that efficiency is no longer guaranteed, as the bidder with the highest valuation is not necessarily the one that wins the object.

\section{CONCLUSIONS}

This computational experiment is focused on a specific dynamic ascending multiunit auction with implementation of Vickrey pricing, which is referred to as the Ausubel auction. 
An independent private values framework with dropout information in which bidders have weakly diminishing marginal values has been employed.

A GA has been introduced that can be successfully employed to evolve bidding strategies for this auction format. The GA proposes the bidding strategy for one bidder (bidder 1) while the others participants keep bidding sincerely. The algorithm generates different bidding strategies or actions to be taken according to the auction conditions, which are defined by three indicators: tendency toward elasticity in price demand; the number of bidders active in the auction with respect to the bidders at the beginning of the auction; and the number of objects that have not been clinched with respect to the number of objects demanded by the GA bidder.

By relating the GA strategy to a specific bidder it is possible to compare the payoff to what he would have obtained by bidding sincerely. The experiments have been run with two different demand curves: elastic and inelastic. The experiments were conducted separately for different numbers of bidders $(n=4,6,8)$ and numbers of objects auctioned $(M=10,15$, 20, and 25). For all environments, three rationing rules have been considered: PRR, SRR, and CRR. For each rationing rule and environment the algorithm was ran 25 times, which allowed a population of 30 individuals to evolve for 1,000 generations.

The evaluation of the GA strategy reveals that the algorithm proposes strategies that yield to equal or higher payoffs to the evolving bidder when rationing is needed. These results do not contradict Ausubel findings because the optimal strategy that the GA propose is not an equilibrium. This is just the best strategy that the evolving bidder can follow once he has learnt his rivals' preferences, the rationing rule considered, and taking into account that the other bidders will always bid sincerely.

To have a better understanding of the behavior of the GA bidder it has been analyzed in depth the auction process of six examples for each rationing rule where the GA beats the SB. With this analysis the optimal bidding strategy, which the GA proposes for bidder $i$ is usually to overbid just until (i) the total demand of the other bidders plus the quantity he has already clinched is equal to the number of lots auctioned, and (ii) what he will probably get with the tie-breaking rule considered is connected with his true values. At that point the bidder will underbid by either making his lower possible bid, i.e., what he has already clinched or underbidding. With this performance the bidder is pushing the auction to a situation of rationing, which maximizes his payoff. In all studied examples, bidder 1 is always better off following the GA strategy. The seller is always worse off with the SRR and the CRR but with the PRR his revenues can change. The outcome of the other participants will depend on each specific auction for the PRR and the SRR but would always be worse off with the CRR.

These results reveal that the implementation of GAs and the selection of a rationing rule can be a key point in the final outcome of an Ausubel auction, both in allocations and payments. Just as some authors pointed out (Jackson et al. 2002), the tie-breaking rules should be viewed as part of the solution of the games rather than part of the description of the model. Therefore, a solution is a tie-breaking rule together with a profile of (mixed) strategies that satisfies the usual best response criterion.

Nevertheless, the constraint set by all bidders but one bidding sincerely is a strong one. In future works all the participants will evolve according to the GA searching for equilibrium.

\section{ACKNOWLEDGMENTS}

This article has been partially financed by the Spanish-funded research MCyT project OPLINK, reference TIN2005-08818-C04-02. 


\section{REFERENCES}

ANDREONI, J., and J. H. MiLlER. 1995. Auctions with artificial adaptive agents. Games and Economic Behaviour, 10:39-64.

ANTHONY, P., and N. R. JENNINGS. 2002. Evolving bidding strategies for multiple Auctions. In Proceedings of the 15th European Conference on Artificial Intelligence, Lyon, France, pp. 178-182.

ANTHONY, P., and N. R. JENNINGS. 2003. Developing a bidding agent for multiple heterogeneous auctions. ACM Transactions on Internet Technology, 3(3):185-217.

Ausubel, L. M. 1997. An efficient ascending-bid auction for multiple objects. Number 97-06 Working Paper. University of Maryland.

Ausubel, L. M. 2004. An efficient ascending-bid auction for multiple objects. American Economic Review, 94:1452-1475.

BIKHCHANDANI, S., and J. M. OstROY. 2006. Ascending price Vickrey auctions. Games and Economic Behaviour, 55(2):215-241.

CLIFF, D. 2003. Exploration in evolutionary design of online auction market mechanisms. Electronic Commerce Research and Applications, 2(2):162-175.

DAWID, H. 1999. On the convergence of genetic learning in a double auction market. Journal of Economic Dynamics and Control, 23:1545-1567.

DIRK, E., and V. GRIMM. 2004. Bidding behavior in multi-unit auctions: An experimental investigation. Number AD-12 Working Paper. IVIE.

GRESIK, T. A. 2001. Rationing rules and European Central Bank auctions. Journal of International Money and Finance, 20(6):793-808.

JACKson, M. O., L. K. Simon, J. M. Swinkels, and W. R. ZAME. 2002. Communication and equilibrium in discontinuous games of incomplete Information. Econometrica, 70:1711-1740.

KAGEL, J. H., S. KINROSS, and D. LEVIN. 2004. Implementing efficient multi-object auctions institutions: An experimental study of the performance of boundedly rational agents. Number 11/04 Working Paper. Ohio State University.

KAGEL, J. H., and D. LEVIN. 2001. Behaviour in multi-unit demand auctions: Experiments with uniform price and dynamic Vickrey auctions. Econometrica, 69(2):413-454.

Kagel, J. H., L. Ye, and S. PevnitsKa. Survival auctions. Number 414 in Econometric Society 2004 North American Winter Meetings, 2004.

KLEMPERER, P. 2000. The Economic Theory of Auctions, Vol. I, II. Edward Elgar, Cheltenham, UK.

Klemperer, P. 2003. Auctions: Theory and Practice. Princeton University Press, Princeton, NJ.

KrishnA, V. 2002. Auction Theory. San Diego Academic Press, San Diego, CA.

Manelli, A., M. Sefton, and B. Wilner 2000. Multi-unit auctions: A comparison of static and dynamic mechanisms. Number 2132867 Working Paper. Arizona State University.

Milgrom, P. 2004. Putting Auction Theory to Work. Cambridge University Press, Cambridge, UK.

Mitchell. M. 1996. An Introduction to Genetic Algorithms. MIT Press, Cambridge, MA.

Mochon, A., D. QUINTANA, P. ISASI, and Y. SAEZ. 2005a. Genetic algorithms versus human bidding strategies for auctions. In Soft Computing as Transdisciplinary Science and Technology, Springer Verlag, Berlin, Germany, 619-628.

Mochon, A., D. QuintANA, Y. SAEZ, and P. ISASI. 2005b. Analysis of Ausubel auctions by means of evolutionary computation. In IEEE Congress on Evolutionary Computation, Vol. 3 in Lecture Notes in Computer Science, IEEE Press, Hoboken, NJ, 2645-2652.

NumnOnda, T., and U. D. ANNAKKage. 1999. Optimal power dispatch in multimode electricity market using genetic algorithm. Electric Power Systems Research, 49(3):211-220.

Perry, M., and P. J. ReNY. 2002. An efficient auction. Econometrica, 70(3):1199-1212. 
Perry, M., and P. J. Reny. 2005. An efficient multi-unit ascending Auction. Review of Economic Studies, 72(2):567-592.

SIMON, L., and W. ZAME. 1990. Discontinuous games and endogenous sharing rules. Econometrica, 58:861-872.

SunNevaG, K. J. 2001. Auction design for the allocation of emission permits. Number 5-01 Working Paper. University of California, Santa Barbara.

VICKREY, W. 1961. Counterspeculation, auctions and competitive sealed tenders. Journal of Finance, 16:8-37.

WEN, F. S., and A. K. DAVID. 2001. Strategic bidding for electricity supply in a day-ahead energy market. Electric Power Systems Research, 59(3):197-206.

\section{APPENDIX A: AN EXAMPLE OF AN AUCTION PROCESS WHERE THE GA BEATS THE SINCERE BIDDING STRATEGY WITH THE PRR}

Bidders' values for $m=15$ and $n=4$ :

$v_{1, k}: 124,93,47,24,13,9,5,3,2,1,1,1,1,1$

$v_{2, k}: 100,72,60,44,22,18,11,6,3,2,2,2,2,1,1$

$v_{3, k}: 198,99,73,46,23,12,7,4,3,2,1,1,1,1,1$

$v_{4, k}: 100,58,41,39,24,16,8,7,4,2,1,1,1,1,1$

TABLE A1. Auction Process and Outcome with Sincere Bidding (SB) for All Bidders

Panel A: Auction Process with SB for All Bidders

\begin{tabular}{cccccccccc}
\hline$P^{I}$ & $Q^{I}$ & $q_{1}^{I}$ & $C_{2}^{I}$ & $q_{2}^{I}$ & $C_{2}^{I}$ & $q_{3}^{I}$ & $C_{3}^{I}$ & $q_{4}^{I}$ & $C_{4}^{I}$ \\
\hline 10 & 24 & 5 & 0 & 7 & 0 & 6 & 0 & 6 & 0 \\
11 & 23 & 5 & 0 & 6 & 0 & 6 & 0 & 6 & 0 \\
12 & 22 & 5 & 0 & 6 & 0 & 5 & 0 & 6 & 0 \\
13 & 21 & 4 & 0 & 6 & 0 & 5 & 0 & 6 & 0 \\
16 & 20 & 4 & 0 & 6 & 1 & 5 & 0 & 5 & 0 \\
18 & 19 & 4 & 0 & 5 & 1 & 5 & 1 & 5 & 1 \\
22 & 18 & 4 & 1 & 4 & 1 & 5 & 2 & 5 & 2 \\
23 & 17 & 4 & 2 & 4 & 2 & 4 & 2 & 5 & 3 \\
24 & 15 & 3 & 3 & 4 & 4 & 4 & 4 & 4 & 4 \\
\hline
\end{tabular}

Panel B: Auction Outcome with SB for All Bidders

\begin{tabular}{|c|c|c|c|c|c|c|c|}
\hline & \multicolumn{4}{|c|}{ Price Paid for the Units Clinched } & \multirow[b]{2}{*}{ Final Allocation } & \multirow[b]{2}{*}{ Final Payment } & \multirow[b]{2}{*}{ Payoff } \\
\hline & 1st Unit & 2nd Unit & 3rd Unit & 4th Unit & & & \\
\hline Bidder 1 & 22 & 23 & 24 & & $q_{1}^{*}=3$ & $P_{1}^{*}=69$ & 195 \\
\hline Bidder 2 & 16 & 23 & 24 & 24 & $q_{1}^{*}=4$ & $P_{1}^{*}=87$ & 189 \\
\hline Bidder 3 & 18 & 22 & 24 & 24 & $q_{1}^{*}=4$ & $P_{1}^{*}=88$ & 328 \\
\hline Bidder 4 & 18 & 22 & 23 & 24 & $q_{1}^{*}=4$ & $P_{1}^{*}=87$ & 151 \\
\hline
\end{tabular}

Seller's revenue $=331$ 
TABLE A2. Auction Process and Outcome with Sincere Bidding (SB) for $i \neq 1$ and Bidder 1 following the GA Strategy

Panel A: Auction Process with SB for $i \neq 1$ and Bidder 1 following the GA Strategy

\begin{tabular}{llrrrrrrrr}
\hline$P^{I}$ & $Q^{I}$ & $q_{1}^{I}$ & $C_{2}^{I}$ & $q_{2}^{I}$ & $C_{2}^{I}$ & $q_{3}^{I}$ & $C_{3}^{I}$ & $q_{4}^{I}$ & $C_{4}^{I}$ \\
\hline 10 & 29 & 10 & 0 & 7 & 0 & 6 & 0 & 6 & 0 \\
11 & 28 & 10 & 0 & 6 & 0 & 6 & 0 & 6 & 0 \\
12 & 27 & 10 & 0 & 6 & 0 & 5 & 0 & 6 & 0 \\
13 & 25 & 8 & 0 & 6 & 0 & 5 & 0 & 6 & 0 \\
16 & 24 & 8 & 0 & 6 & 0 & 5 & 0 & 5 & 0 \\
18 & 23 & 8 & 0 & 5 & 0 & 5 & 0 & 5 & 0 \\
22 & 22 & 8 & 1 & 4 & 0 & 5 & 0 & 5 & 0 \\
23 & 21 & 8 & 2 & 4 & 0 & 4 & 0 & 5 & 0 \\
24 & 14 & 2 & & 4 & & 4 & & 4 &
\end{tabular}

Panel B: Auction Outcome with SB for $i \neq 1$ and Bidder 1 following the GA Strategy

Price Paid for the Units Clinched

1st Unit 2nd Unit 3rd Unit 4th Unit Final Allocation Final Payment Payoff

\begin{tabular}{llllllll}
\hline Bidder 1 & 22 & 23 & 23 & & $q_{1}^{*}=3$ & $P_{1}^{*}=68$ & 196 \\
Bidder 2 & 23 & 23 & 23 & 23 & $q_{2}^{*}=4$ & $P_{2}^{*}=92$ & 184 \\
Bidder 3 & 23 & 23 & 23 & 23 & $q_{3}^{*}=4$ & $P_{3}^{*}=92$ & 324 \\
Bidder 4 & 23 & 23 & 23 & 23 & $q_{4}^{*}=4$ & $P_{4}^{*}=92$ & 146
\end{tabular}

Seller's revenue $=344$

\section{APPENDIX B: AUCTION OUTCOMES WITH THE SRR AND THE CRR}

TABLE B1. Payoff Average for Sincere Bidding (SB) and GA Bidding Strategies with SRR

\begin{tabular}{|c|c|c|c|c|c|c|c|c|}
\hline & \multicolumn{2}{|c|}{$m=10$} & \multicolumn{2}{|c|}{$m=15$} & \multicolumn{2}{|c|}{$m=20$} & \multicolumn{2}{|c|}{$m=25$} \\
\hline & SB & GA & SB & GA & SB & GA & SB & GA \\
\hline $\begin{array}{l}\text { Elastic } \\
n=4\end{array}$ & $\begin{array}{c}80.68 \\
(30.74)\end{array}$ & $\begin{array}{c}81.00 \\
(30.72) \\
\mathbf{0 . 3 2}\end{array}$ & $\begin{array}{l}179.88 \\
(34.15)\end{array}$ & $\begin{array}{c}182.36 \\
(34.16) \\
\mathbf{2 . 4 8}\end{array}$ & $\begin{array}{c}245.04 \\
(46.85)\end{array}$ & $\begin{array}{c}247.64 \\
(47.28) \\
\mathbf{2 . 6 0}\end{array}$ & $\begin{array}{c}311.76 \\
(63.52)\end{array}$ & $\begin{array}{c}314.56 \\
(63.69) \\
\mathbf{2 . 8 0}\end{array}$ \\
\hline$n=6$ & $\begin{array}{c}80.08 \\
(25.04)\end{array}$ & $\begin{array}{c}81.08 \\
(25.06) \\
\mathbf{1 . 0 0}\end{array}$ & $\begin{array}{l}127.32 \\
(34.56)\end{array}$ & $\begin{array}{c}129.52 \\
(34.97) \\
\mathbf{2 . 2 0}\end{array}$ & $\begin{array}{l}159.04 \\
(33.21)\end{array}$ & $\begin{array}{c}161.56 \\
(33.53) \\
\mathbf{2 . 5 2}\end{array}$ & $\begin{array}{l}184.12 \\
(33.54)\end{array}$ & $\begin{array}{c}188.44 \\
(33.73) \\
\mathbf{4 . 3 2}\end{array}$ \\
\hline$n=8$ & $\begin{array}{c}29.40 \\
(14.46)\end{array}$ & $\begin{array}{c}29.40 \\
(14.46) \\
\mathbf{0 . 0 0}\end{array}$ & $\begin{array}{c}93.24 \\
(28.79)\end{array}$ & $\begin{array}{c}93.84 \\
(28.82) \\
\mathbf{0 . 6 0}\end{array}$ & $\begin{array}{c}85.92 \\
(25.35)\end{array}$ & $\begin{array}{c}89.44 \\
(26.59) \\
\mathbf{3 . 5 2}\end{array}$ & $\begin{array}{l}114.40 \\
(28.26)\end{array}$ & $\begin{array}{c}117.64 \\
(28.55) \\
\mathbf{3 . 2 4}\end{array}$ \\
\hline
\end{tabular}


TABLE B1. Continued

\begin{tabular}{|c|c|c|c|c|c|c|c|c|}
\hline & \multicolumn{2}{|c|}{$m=10$} & \multicolumn{2}{|c|}{$m=15$} & \multicolumn{2}{|c|}{$m=20$} & \multicolumn{2}{|c|}{$m=25$} \\
\hline & SB & GA & SB & GA & SB & GA & SB & GA \\
\hline $\begin{array}{l}\text { Inelasti } \\
n=4\end{array}$ & $\begin{array}{l}126.88 \\
(13.54)\end{array}$ & $\begin{array}{c}127.52 \\
(13.63) \\
\mathbf{0 . 6 4}\end{array}$ & $\begin{array}{l}196.92 \\
(12.48)\end{array}$ & $\begin{array}{c}199.48 \\
(12.74) \\
\mathbf{2 . 5 6}\end{array}$ & $\begin{array}{c}260.88 \\
(20.56)\end{array}$ & $\begin{array}{c}267.16 \\
(20.97) \\
6.28\end{array}$ & $\begin{array}{c}293.36 \\
(20.09)\end{array}$ & $\begin{array}{c}299.80 \\
(19.96) \\
\mathbf{6 . 4 4}\end{array}$ \\
\hline$n=6$ & $\begin{array}{c}79.76 \\
(13.76)\end{array}$ & $\begin{array}{c}79.80 \\
(13.75) \\
\mathbf{0 . 0 4}\end{array}$ & $\begin{array}{c}131.28 \\
(17.62)\end{array}$ & $\begin{array}{c}132.12 \\
(18.05) \\
\mathbf{0 . 8 4}\end{array}$ & $\begin{array}{c}173.56 \\
(17.79)\end{array}$ & $\begin{array}{c}177.04 \\
(18.53) \\
\mathbf{3 . 4 8}\end{array}$ & $\begin{array}{c}185.12 \\
(13.30)\end{array}$ & $\begin{array}{c}186.92 \\
(13.58) \\
\mathbf{1 . 8 0}\end{array}$ \\
\hline$n=8$ & $\begin{array}{c}53.88 \\
(11.09)\end{array}$ & $\begin{array}{c}55.96 \\
(11.39) \\
\mathbf{2 . 0 8}\end{array}$ & $\begin{array}{c}84.24 \\
(11.73)\end{array}$ & $\begin{array}{c}87.32 \\
(11.17) \\
\mathbf{3 . 0 8}\end{array}$ & $\begin{array}{l}126.52 \\
(14.76)\end{array}$ & $\begin{array}{c}130.52 \\
(15.00) \\
\mathbf{4 . 0 0}\end{array}$ & $\begin{array}{l}186.48 \\
(15.99)\end{array}$ & $\begin{array}{c}189.64 \\
(15.74) \\
\mathbf{3 . 1 6}\end{array}$ \\
\hline
\end{tabular}

Standard errors of the mean in parentheses. Payoff differences form SB in bold.

TABLE B2. Payoff Average for Sincere Bidding (SB) and GA Bidding Strategies with CRR

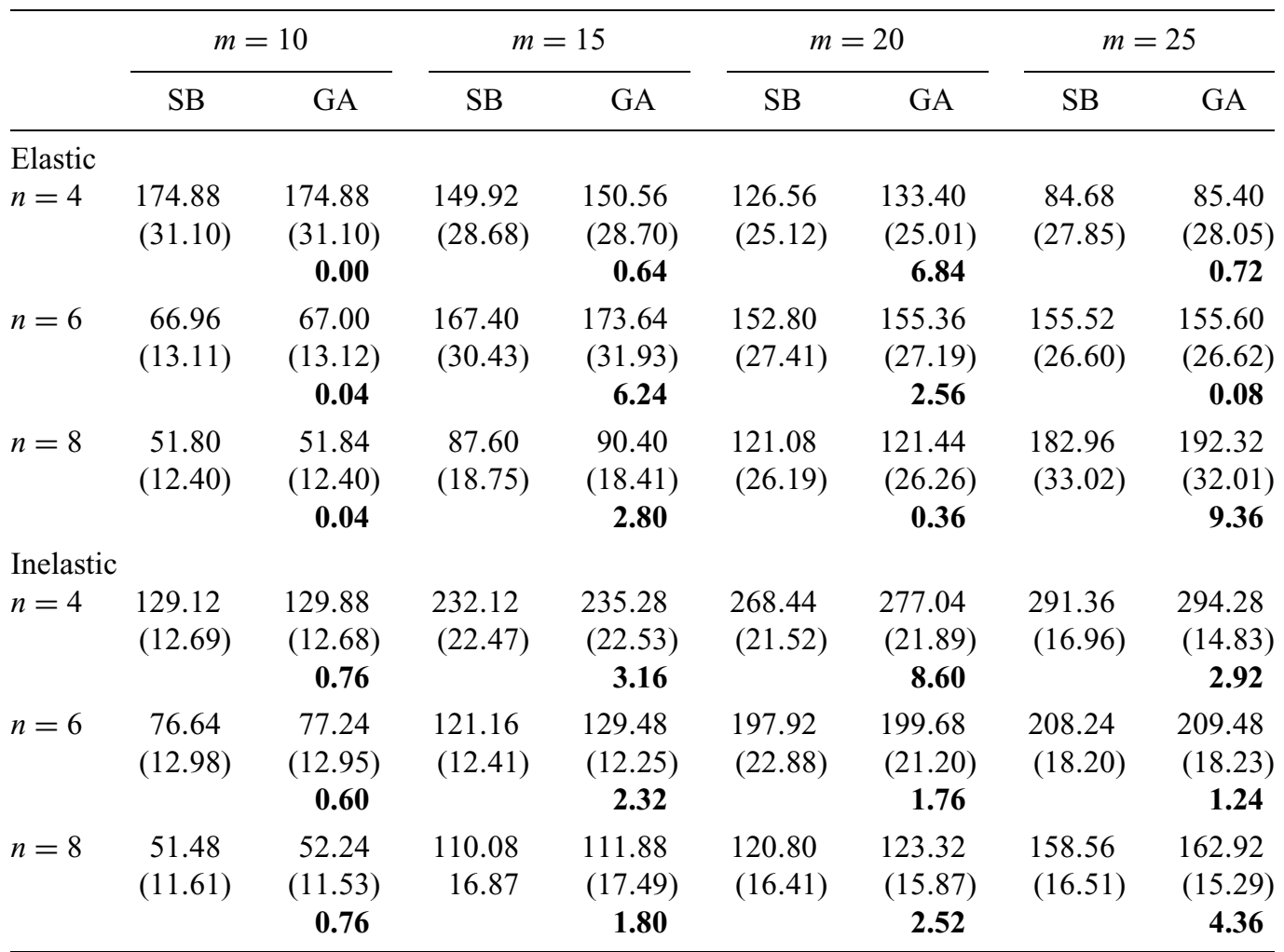

Standard errors of the mean in parentheses. Payoff differences form SB in bold. 